\title{
A Flecha de Dois Gumes: o tempo redimensionado em Memórias póstumas de Brás Cubas, de Machado de Assis
}

\author{
Ágata Cristina Kaiser Dumont
}

\begin{abstract}
Resumo
O tempo não se apresenta somente como elemento estruturador, mas como recurso artístico em Memórias póstumas de Brás Cubas. O tempo aqui apresentado transcende a limitação de aspecto constituinte da narrativa e surge, na obra em questão, como mais um instrumento utilizado pelo escritor para a construção da arte literária.
\end{abstract}

Palavras-chave: Teoria da Literatura. Tempo. Machado de Assis. Memórias póstumas de Brás Cubas.

Mas é isso mesmo que nos faz senhores da terra, é esse poder de restaurar o passado, para tocar a instabilidade das nossas impressões e a vaidade dos nossos afetos.

Machado de Assis

O presente trabalho tem como objetivo analisar alguns aspectos do tempo existentes na obra Memórias póstumas de Brás Cubas, de Machado de Assis. Escolhemos três tópicos específicos relacionados ao tempo, uma vez que tanto o assunto quanto a obra em questão já foram bastante estudados. Além de Machado de Assis possuir uma fortuna crítica extensa, o tempo é também matéria que tange diversas áreas de estudo, tais como a física, a biologia, a filosofia, a psicologia e as artes, como a música, o teatro, a literatura. Não obstante perpassarmos por campos do conhecimento alheios à literatura, o nosso enfoque foi o tempo como recurso literário capaz de suscitar determinados efeitos de sentido no leitor. Dessa forma, o tempo na literatura transcende a definição de elemento estruturador da narrativa, adquirindo outras tantas possibilidades.

É consenso entre importantes críticos machadianos, como Antonio Candido, Guilherme Merquior, Roberto Schwarz e ainda Ronaldes de Melo e Souza, que o tempo é um aspecto decisivo em Memórias póstumas de Brás Cubas. Isso pode ser percebido pelos saltos temporais, pelo jogo com o leitor, pela alteração constante do narrador e ainda pela insistência do narrador em lembrar ao leitor a transitoriedade do homem e das coisas no tempo. Guilherme Merquior, em um texto de 1978 sobre as Memórias póstumas de Brás Cubas, enfatiza a consciência de Machado de Assis em construir uma 
narrativa literária explicitamente artificial, sem pretensões de "fingir-se" verdadeira ao leitor (MERQUIOR, 1972, p. 20). Essa consciência do escritor em relação à artificialidade da literatura aproxima a narrativa machadiana daquilo que Baudelaire definiu como moderno: "A modernidade é o transitório, o efêmero, o contingente, é metade da arte, sendo a outra metade o eterno e o imutável." (BAUDELAIRE, 1995, p. 859). É interessante observar que este paradoxo proposto por Baudelaire ocorre especificamente na relação entre a arte, seus instrumentos de construção e sua permanência no tempo.

A primeira abordagem que fazemos neste trabalho é analisar como o tempo do enunciado e o tempo da enunciação se misturam nesta obra machadiana. Brás Cubas, em suas memórias, explicita os efeitos do tempo desde a dedicatória "ao verme que primeiro roeu as frias carnes de [seu] cadáver." (ASSIS, 1981, p. 11.). Verme este responsável pelo corpo apodrecido, mas que não interfere de forma nenhuma no corpo "de papel", no qual Brás Cubas supostamente se transformou após a morte, possibilitando a eternidade por meio das sucessivas edições de si mesmo.

Em um segundo momento, Brás se refere à teoria das edições humanas comparando o homem a uma "errata pensante", que vai sendo corrigida em cada edição até o editor dá-la "de graça aos vermes". Mesmo sobrepondo-se aos vermes pelo formato de livro, eternamente reeditável, Brás Cubas compara o homem justamente à parte do livro que pode ser alterada. O livro, assim, apresenta-se também provisório, tal como a carne a ser carcomida pelos vermes (BAPTISTA, 2003, p. 235.).

Apesar do paradoxo explícito, Brás não se intimida em tentar romper a transitoriedade, a princípio por enfatizar a construção do nome "Cubas", falso, mas digno por escapar à tanoaria - ofício do tataravô, que dera origem à família. Depois, procura propagar o nome ao tentar criar um medicamento contra a melancolia, "mal da humanidade" - o "emplasto Brás Cubas" - que, antes de Ihe dar a fama almejada, ironicamente, o leva à morte. Com a morte, resta a Brás Cubas a narração, única alternativa para permanecer no tempo, no imaginário de seus leitores.

A essa discussão filosófica sobre o tempo, porém, sobrepõe-se com bastante visibilidade a narrativa de Brás Cubas, cronologicamente invertida, já que o narrador principia contando a própria morte. Apesar de direcionar o caráter corrosivo das memórias à maneira de uma epígrafe, a morte apresenta-se, para Brás, como um "segundo nascimento", já que é só a partir dela que Brás torna-se um "autor", como ele mesmo o diz:

Algum tempo hesitei se devia abrir estas memórias pelo princípio ou pelo fim, isto é, se poria em primeiro lugar o meu nascimento ou a minha morte. Suposto o uso vulgar seja começar pelo nascimento, duas considerações me levaram a adotar diferente método: a primeira é que eu não sou propriamente um autor defunto, mas um defunto autor, para quem a campa foi outro berço; a segunda é que o escrito ficaria assim mais galante e mais novo. Moisés, que também contou a sua morte, não a pôs no intróito, mas no cabo: diferença radical entre este livro e o Pentateuco. (ASSIS, 1981, p. 13).

A morte, no entanto, aparece também como uma vitória de Brás Cubas sobre o tempo, já que, a partir dela, o narrador habita o atemporal - a eternidade. Isto ainda possibilita a Brás criticar e ironizar a sociedade, já que não está mais submetido às regras sociais.

Além de começar a narrativa pela morte, as digressões temporais em Memórias póstumas de Brás Cubas são bastante freqüentes, vistas durante muito tempo como defeito na escrita. Tais digressões estruturais se apresentam, no entanto, como reflexos das digressões ocorridas na vida de Brás Cubas. O narrador apresenta uma 
história de si mesmo sempre alheia ao tempo socialmente imposto ao homem: não se casou quando deveria, então, nunca se casou; não conseguiu o cargo profissional almejado quando era tempo, então, nunca trabalhou; em suma, a quebra no "tempo convencional" ocasionou-lhe uma vida estéril, como se fora uma punição por não se ter mantido dentro dos padrões.

Mesmo tendo-se utilizado da morte para permanecer vivo, para conseguir aquilo que, em vida, falhou - a imortalidade - Brás constrói sua narrativa de forma a manter o leitor atento até o fim do livro. Se sua vida carece de emoção, o narrador busca manter o leitor pelos recursos temporais que insere em seu texto. Brás tem consciência de que sua "imortalidade" está ligada ao tempo narrado, ao espaço limitado do livro e ao tempo de leitura. Para prolongar sua existência, Brás, então, funde sua história à narrativa, priorizando o discurso, a linguagem, preterindo os fatos em função do processo da escritura.

A segunda abordagem que fazemos é do tempo como transformador da identidade de Brás Cubas, que apresenta alterações tanto como personagem quanto como narrador. Vimos, com Meyerhoff, que o tempo é um aspecto intrinsecamente ligado ao conceito do eu (MEYERHOFF, 1976, p. 1-2). O tempo irregular, interrompido e saltitante que se apresenta em Memórias póstumas de Brás Cubas corresponde ao sujeito de Brás, também irregular, interrompido e saltitante. Essas características legaram a Brás Cubas o adjetivo "volúvel", sofrendo o narrador, segundo Schwarz, de uma constante "desidentificação" de si mesmo (SCHWARZ, 1990, p. 29-33).

Qualquer narrativa em primeira pessoa apresenta uma diferenciação, por mais sutil que seja, entre o "eu narrado" e o "eu narrante" (termos de Stanzel) (SCHWARZ, 1990, p. 29-33). Há, necessariamente, um espaço de tempo entre o fato ocorrido e o momento de narrá-lo, o que pode gerar mudanças nesse sujeito "personagem" para o sujeito "narrador". Em Memórias póstumas de Brás Cubas, porém, a diferença de tempo entre o "eu narrado" e o "eu narrante" é indefinida, pois há a morte e o tempo da decomposição do corpo antes de se iniciar a narrativa - como vimos, as memórias são dedicadas ao verme que lhe roeu as carnes.

Essa distância temporal dificulta a identificação do leitor vivo com o defunto autor, necessitando Brás de um novo leitor, capaz de compreender não só o processo artificial da escrita, como os comentários e reflexões de um morto, fugindo, assim, de esperar no enredo ou na verossimilhança o fio condutor do romance.

A forma em que Brás Cubas se apresenta ao leitor - morto - deixa à mostra a consciência do defunto autor tanto em relação à própria ficcionalidade quanto à própria existência limitada durante a leitura, revelando a construção explicitamente artificial de Machado de Assis. As memórias que compõem a narrativa, então, apresentam-se também tão artificiais quanto o próprio narrador-personagem. Deleuze sugere que só o presente exista, sendo o passado e o futuro redimensionados na flecha do tempo. A memória, como passado que se revitaliza no presente, só existe, no livro, no momento da leitura.

A permanente indecidibilidade de Brás Cubas se compara à definição de beleza artística proposta por Baudelaire. O poeta e crítico francês desvia o conceito dos padrões clássicos de beleza ao inserir-lhe a dupla dimensão da convivência entre o eterno e o provisório. O defunto autor, como vimos, apesar de ter conseguido a imortalidade, ainda assim se mantém em constante oscilação, abraçando na ficção o que Baudelaire teoricamente postulava.

Vale observar que as freqüentes desidentificações de Brás Cubas se associam imediatamente, segundo Schwarz, a fatos históricos nacionais, visto ser a história do 
Brasil repleta de alterações teóricas em espaços curtos de tempo. Aqui, mais uma vez, Machado de Assis mescla o transitório, o efêmero dos aspectos sociais de seu tempo aos valores humanos universais na figura de Brás Cubas, imortalizando-o pela arte.

A terceira possibilidade do tempo que abordamos em Memórias póstumas de Brás Cubas é o recurso utilizado por Brás para burlar o leitor. O caráter elíptico e fragmentário do texto machadiano, antes visto como defeito narrativo, foi percebido por Antonio Candido como um aspecto inovador do romance.

O gênero, porém, começava a construir um novo público leitor na Europa, constituído basicamente por mulheres ou homens que não trabalhavam, mas com pouca instrução para acompanhar narrativas mais sofisticadas. No Brasil, o romance é introduzido pelo Romantismo, solicitando narradores que levem o leitor "pela mão" adentro da narrativa, já que o público não era habituado a tal tipo de leitura (LAJOLO, 2004 , p. 141). Wolfang Iser analisa a obra literária partindo do pressuposto de que só há leitura efetiva quando o leitor preenche as lacunas do texto. As projeções do próprio leitor, no entanto, devem se alterar para preencher tais lacunas, exigindo uma "desautomatização" de quem lê.

Iser analisa como os vazios do texto aparecem em três tipos de narrativa. No romance de tese os vazios são praticamente ausentes, já que o texto é utilizado para veicular determinado ponto de vista, devendo-se evitar, então, a ambigüidade. No romance-folhetim os vazios são cortes propositais nos momentos de tensão da narrativa para forçar o público leitor a adquirir o próximo capítulo, ou seja, uma estratégia puramente comercial. No romance haveria, segundo o teórico, espaço para lacunas propositais a serem preenchidas com projeções do leitor, uma vez que o tipo de narrativa é livre para se construir como arte, sem função de direcionar a compreensão do leitor ou de manipulá-lo com a omissão dos fatos narrados (ISER, 1979, p. 107-118). Apesar de Memórias póstumas de Brás Cubas ter sido publicada em folhetins, o escritor não trata a obra como mero comércio. O interesse artístico e, como vimos, de eternidade - se mantém mesmo quando os capítulos são compilados em livro.

Sendo o romance um gênero novo no Brasil, ainda conquistando um público leitor, a narrativa fluente, contínua e sem interrupções que pudessem perturbar a compreensão do texto seria ideal. Machado de Assis, no entanto, quebra essa expectativa do leitor, subvertendo a ordem nas memórias de Brás Cubas, fazendo do texto literário um desafio ao leitor pelo excesso de lacunas, que se apresentam na obra tanto nos vazios deixados entre a publicação dos folhetins como nos vazios do próprio enredo, falciforme. O narrador criado por Machado em Memórias póstumas de Brás Cubas difere daquele a que o leitor brasileiro estava acostumado. Brás Cubas se recusa a facilitar os caminhos que levam o leitor para dentro da obra literária.

Reconstruir a flecha do tempo que constitui a história de Brás Cubas, então, é trabalho do leitor. Rever os próprios pontos de vista para captar o mundo adverso de onde parte a narrativa de Brás Cubas também é trabalho do leitor. Compreender que, na morte, a flecha do tempo tem dois gumes e pode ser maleável, como Brás a dispõe nas suas memórias, é, mais uma vez, trabalho do leitor. E ainda, perceber que essa mesma flecha que coordena o tempo nas Memórias póstumas de Brás Cubas, sendo maleável, não é linear, e sim espiral, é trabalho do leitor.

Ao desabafar a um crítico, no capítulo CXXXVIII: "Valha-me Deus! é preciso explicar tudo" (ASSIS, 1981, p. 131), Brás deixa a dica a seu futuro leitor para que este busque compreender a obra sem esperar muitas explicações do narrador. Assim, os vazios excessivos da obra machadiana podem ser completados com as impressões, 
os valores e o conhecimento também de outros tempos, que alteram o passado e ampliam as possibilidades de leitura. Restaurar o passado, como sugere Brás Cubas na epígrafe dessa apresentação, antes de "tocar a instabilidade de nossas impressões", é construir o instável dentro daquilo que se pretende eterno, como o faz Machado de Assis nesta obra.

Abstract

Narrative time is not only a structural element, but a special artistic resource in Memórias póstumas de Brás Cubas. Time here represented transcends its limitations as a constituent aspect of the narrative and appears as one more tool used by the author in his personal process of literary creation.

Key words: Theory of Literature. Time. Machado de Assis. Memórias póstumas de Brás Cubas.

\section{Referências}

ASSIS, Machado de. Memórias póstumas de Brás Cubas. 8.ed. São Paulo: Ática, 1981.

BAPTISTA, Abel Barros. A formação do nome: duas interrogações sobre Machado de Assis. Campinas: Ed. UNICAMP, 2003.

BAPTISTA, Abel Barros. Autobibliografias: solicitação do livro na ficção de Machado de Assis. Campinas: Ed. UNICAMP, 2003.

BARTHES, Roland. A morte do autor. In: O rumor da língua. Tradução de Mário Laranjeira. São Paulo: Brasiliense; Campinas: Ed. Unicamp, 1988.

BAUDELAIRE, Charles. O pintor na vida moderna. In: Charles Baudelaire - Poesia e Prosa. Org. Ivo Barroso. Rio de Janeiro: Nova Aguilar, 1995.

CANDIDO, Antonio. Vários escritos. São Paulo: Duas Cidades, 1970.

DELEUZE, Gilles. Diferença e repetição. Trad. Luiz Orlandi e Roberto Machado. Rio de Janeiro: Graal, 1988.

ISER, Wolfgang. $O$ ato da leitura: uma teoria do efeito estético. São Paulo: Ed. 34, 1999.

LAJOLO, Marisa. Como e por que ler o romance brasileiro. São Paulo: Objetiva, 2004.

MERQUIOR, José Guilherme. Gênero e estilo das Memórias póstumas de Brás Cubas. In: COLÓQUIO LETRAS, 8., 1972. Lisboa.

MEYERHOFF, Hans. O tempo na literatura. Tradução de Myriam Campello. São Paulo: McGraw-Hill do Brasil, 1976. 
SCARPELLI, Marli de Oliveira Fantini. Machado de Assis entre a tradição e a modernidade. In: CANIATO, Benilde Justo; MINÉ, Elza (Coord. e Ed.). Abrindo caminhos: homenagem a Maria Aparecida Santilli. Col. Via Atlântica, n. 2. São Paulo: FFLCH/USP, 2002.

SCHWARZ, Roberto. Um mestre na periferia do capitalismo: Machado de Assis. São Paulo: Duas Cidades / Ed. 34, 2000.

SOUZA, Ronaldes de Melo. O estilo narrativo de Machado de Assis. In: Machado de Assis: uma revisão. Rio de Janeiro: In-folio, 1998. 